21. Мухаметшина Н.С., Кандауров С.П., Явкин Н.В. «Новые мигранты» в региональном сообществе: практики взаимодействия и интеграционный потенциал / под ред. Н.С. Мухаметшиной. Самара: Самар. гос. арх.-строит. ун-т, 2011. 108 с.

22. Кандауров С.П. Факторы восприятия иммигрантов старожильческим населением (на примере Самарской области) // Аспирантский вестник Поволжья. 2013. № 7-8. С. 130-135.
23. Мокин К.С. Социальная мобильность мигранта в поликультурной среде // Измерение культурного многообразия. Языковая ситуация, переписи, полевая этностатистика / ред. М.Ю. Мартынов, В.В. Степанов. М.: ИЭА РАН, 2019. С. 208-224.

Исследование выполнено при поддержкке РФФИ и Правительства Самарской области в рамках научного проекта №№ 18-411-630002.

\title{
TRADITIONAL CULTURE OF MIGRANTS FROM CENTRAL ASIAN COUNTRIES IN THE CONTEXT OF INTEGRATION PRACTICES
}

(C) 2019

Mukhametshina Natalia Semenovna, doctor of political sciences, professor of Philosophy Department Samara State Technical University (Samara, Russian Federation)

Abstract. The paper deals with the results of standardized interviews with representatives of the peoples from Central Asia (Kyrgyz, Tajiks, Uzbeks) currently residing in Samara and the Samara Region. The interviews were conducted in 2018-2019 within the framework of the project supported by the Russian Foundation for Basic Research. It has been established that ethnic culture retains its functionality in a new environment in all groups selected for the study. In particular, national cuisine and ethnic elements for the interior of their houses are widely used. The vast majority know and perform folk songs and music, have their recordings, and many of those people listen to them regularly or from time to time. They keep reading books and periodicals in their native language. Almost all of them keep their language immersion. All groups of respondents noted openness and readiness for friendly contacts regardless of nationality. The overwhelming majority of respondents communicate with their colleagues and neighbors. Communication is predominantly positive. Marital and family behavior reflects a rather positive perception of interethnic marriages. Although the situation in this private sphere is not very clear. Based on the results obtained, the conclusion is that the majority of the representatives of the diaspora communities are successfully integrated.

Keywords: attributes of ethnic culture; traditions; Central Asian countries; Samara Region; multicultural region; diaspora communities; culturally distinguishable migrants; migrants; integration of migrants; ethnic culture; bridge languages; marital and family behavior; social interaction; host community.

\section{«Я И РОДИНУ СОХРАНИЛ, И ЗДЕСЬ Я КАК НА РОДИНЕ»: ОСОБЕННОСТИ ЭТНОКУЛЬТУРНОЙ ИДЕНТИФИКАЦИИ И СОЦИОКУЛЬТУРНОЙ ИНТЕГРАЦИИ САМАРСКИХ ТАДЖИКОВ}

(C) 2019

Ягафова Екатерина Андреевна, доктор исторических наук, профессор,

заведующий кафедрой философии, истории и теории мировой культуры

Самарский государственный соииально-педагогический университет (2. Самара, Российская Федераиия)

Аннотаџия. В статье представлены результаты исследования таджикской диаспоры Самарской области, в ходе которого были выявлены особенности этнической идентификации и социокультурной адаптации членов общины. Исследование базируется на материалах полевого обследования, проведенных в регионе в 20182019 гг., с использованием качественных (глубинные интервью) и количественных методов (анкетирование). Методологическую основу статьи составили теоретико-методологические разработки в области диаспоральных исследований. Основными факторами этнокультурной идентификации самарских таджиков выступают язык, общность происхождения и элементы этнической культуры, представленные в семейно-родственном общении, а также в публичном пространстве региона. Этнические (таджикские) приоритеты в конструировании социокультурного пространства обеспечивают функциональность и воспроизводство культурноязыковых характеристик членов общины и определяют тенденцию к внутриэтнической замкнутости. Вместе с тем контакты с окружающим полиэтническим населением и установка на интеграцию в местную среду (получить образование, гражданство, работу, устроить быт) разрушают моноэтничность социальных связей самарских таджиков, в первую очередь молодого поколения, родившегося в России. Исследование показало, что стратегия социокультурной интеграции самарских таджиков основана на сохранении этнокультурной идентичности, с одной стороны, и восприятии социальных характеристик принимающего сообщества, с другой стороны.

Ключевые слова: самарские таджики; диаспорная группа; община; миграция; этническая культура; этнокультурная идентичность; социокультурная интеграция; адаптация; межэтнические контакты; межэтнические браки; национальная кухня; праздники; религия; полиэтническая среда. 


\section{Постановка проблемы}

Диаспоральные исследования остаются одним из актуальных направлений в современной науке. Диаспоры выходцев из Центральной Азии, сложившиеся преимущественно в ходе миграционных процессов последней четверти XX - начала XXI века, представляют интерес при изучении проблем этничности, идентичности, межкультурного взаимодействия и этнического разнообразия российских регионов. Киргизы, узбеки, таджики и представители некоторых других центральноазиатских народов начали переселяться на территорию современной Самарской области еще со второй половине XX в., но наиболее активно этот процесс протекал в последние три десятилетия, обусловив разнообразные межэтнические контакты с местным населением. Как происходит адаптация мигрантов к условиям полиэтнического региона, какие факторы влияют на формирование и сохранение этнической идентичности в диаспорных группах? Каковы особенности внутриэтнического общения членов общины? Эти вопросы будут рассмотрены в данной статье на примере таджикской диаспоры Самарской области. Под «самарскими таджиками» в данной статье подразумевается все таджикское население Самарской области.

Таджики - одна из многочисленных этнических диаспор выходцев из Средней Азии в России. По данным переписи 2010 г., в стране проживало более 200 тыс. таджиков [1]. Кроме того, ежегодно в России находится свыше 1 млн трудовых мигрантов [2, с. 4].

В Самарской области значительный рост численности таджикского населения наблюдался в течение последних трех десятилетий: по переписи 1989 г. насчитывалось 1598 чел. [3], в 2002 г. - 4624 чел. [4], в 2010 г. - 7195 чел. [1]. Таким образом, с 1989 г. численность таджиков в регионе выросла в 4,5 раза, при этом только в последний межпереписной период (2002-2010 гг.) - в 1,6 раза (см. табл. 1).

Таблица 1 - Численность таджикского населения на территории Самарского края в 1926-2010 гг., чел.

\begin{tabular}{|l|c|c|c|c|c|c|c|c|}
\hline Годы & 1926 & $\begin{array}{c}1939 \\
{[5]}\end{array}$ & 1959 & $\begin{array}{c}1970 \\
{[6]}\end{array}$ & $\begin{array}{c}1979 \\
{[7]}\end{array}$ & 1989 & 2002 & 2010 \\
\hline $\begin{array}{l}\text { Числен- } \\
\text { ность }\end{array}$ & - & 134 & $\begin{array}{c}\text { Не вы- } \\
\text { делены }\end{array}$ & 310 & 702 & 1598 & 4624 & 7195 \\
\hline
\end{tabular}

Как видно из приведенной таблицы, рост (удвоение) наблюдался и в предыдущие годы, что, безусловно, было связано с миграцией в регион таджиков. По неофициальным данным, а именно по мнению руководителей таджикской диаспоры в области, численность этнической группы составляет только в Самаре и Тольятти около 75 тыс. человек [8]. По численности самарская диаспора таджиков занимает 9-е место в РФ.

\section{История и методология вопроса, цель и задачи исследования}

Существенный вклад в изучение феномена диаспоры и диаспорных групп внесли зарубежные (Л. Ашкенази [9], Д. Коэн [10], У. Сафран [11], Г. Шеффер [12] и др.) и отечественные (С.А. Арутюнов [13], В.А. Дятлов [14], В.А. Тишков [15] и многие другие) учёные. Разработаны критерии характеристики диаспорных групп, в их числе: коллективная память о первоначальной родине, чувство отчужденности в «принимающем» обществе, идеализация родины, стремление поддержать ее существование, персональная или коллективная идентичность с ней, готовность сохранять и передавать культурное наследие последующим поколениям, общественные институты [16]. Указанные критерии значимы для изучения таджикской диаспоры.

Тема трудовой миграции из Средней Азии - одна из постоянно изучаемых и обсуждаемых научным сообществом, и значительное место в ней уделяется таджикам. В публикациях поднимаются вопросы социальной интеграции [17-20], в том числе и самарских таджиков [21], но преобладает, как справедливо отмечает Н.А. Зотова, демографический и социально-экономический подходы. Значительно меньше внимания уделяется вопросам этнокультурной адаптации таджиков к полиэтническим регионам России $[2 ; 22 ; 23]$. Вместе с тем именно рассмотрение этнокультурных особенностей позволяет создать полноценный и объемный портрет трудового мигранта, представить насыщенное описание миграционных процессов, а также охарактеризовать жизнь этнической общины в целом.

Определенный вклад в этнологическое исследование таджикских общин в Урало-Поволжье внесли В.В. Амелин [2], Г.Ф. Габдрахманова, Э.А. Сагдиева [24], Н.С. Мухаметшина [25; 26], А.В. Черных [22; 23], С.А. Эркаев, А.С. Эркаев [27] и другие. Однако специального исследования по этнологии самарских таджиков не проводилось, и данная статья является первым опытом. В работе отражены результаты статистического обследования (50 чел.) таджикской общины в Самаре, в ходе которого выяснялись особенности функционирования языков, элементов этнической культуры, характер религиозности членов общины, степень их интегрированности в социальное пространство многонационального региона. Эти данные были существенно дополнены глубинными интервью (5 интервью), позволившими раскрыть отдельные стороны культурно-языковых характеристик самарских таджиков.

Цель исследования: определение факторов этнической идентификации и социокультурной адаптации самарских таджиков в полиэтническом окружении. Задачи исследования: охарактеризовать роль языка, этнической культуры, внутри- и межэтнических взаимодействий, брачных контактов, связей с исторической родиной в ходе этнокультурной идентификации и социокультурной адаптации членов группы.

\section{Анализ данных}

Формирование таджикской общины Самарской области происходило в несколько этапов. Первая волна переселенцев прибыла в 1970-х гг. по направлению Таджикской ССР для учебы в Куйбышевский педагогический институт (ныне - Самарский государственный социально-педагогический университет); большинство из них вернулись на родину дипломированным учителями русского языка и литературы и других предметов, а оставшиеся в Куйбышеве (Самаре) составили основу таджикской диаспоры. Вторая волна миграции связана с последствиями распада СССР и гражданской войны в Таджикистане (1992-1997), по окончании которой часть политических эмигрантов осела в Самаре и активно интегрировалась в местное сообщество, в том числе получила гражданство. Третья волна миграции - трудовые 
мигранты конца XX - начала XXI в., численность которых постоянно меняется. Как правило, их привлекают в качестве низкоквалифицированной и низкооплачиваемой рабочей силы на строительных работах. Выбор Самары и области обусловлен не только экономической привлекательностью региона, но и климатическими условиями, которые выходцы из Средней Азии находят для себя комфортными [28].

Большинство самарских таджиков $(80,9 \%)$ проживает в городах, при этом основная масса городских жителей $(90,9 \%)$ сосредоточена в крупных городах или ближайших пригородах: в г.о. Самара 2333 чел., в г.о. Тольятти - 2095 чел., в г.о. Сызрань - 274 чел., г.о. Чапаевск - 265 чел., г.о. Жигулевск 175 чел., г.о. Новокуйбышевск - 150 чел. [29, табл. 4]. В Самаре более половины таджиков $(56,11 \%)$ проживают в Кировском, Промышленном и Советском районах, где расположены крупные рынки и торговые базы города, доля в других шести районах города составляет от 5 до $10 \%$. В сельской местности таджики расселены также в ближайших к крупных городам районах: Волжском (329 чел.), Ставропольском (202 чел.), Красноярском (140 чел.), Безенчукском (112 чел.), Кинель-Черкасском (108 чел.) [29, с. 42-58].

Следует отметить диспропорцию в половой структуре таджикского населения в области, вызванную, вероятно, особенностями миграционного потока и трудовой занятости, в которые вовлечены именно таджики-мужчины: среди горожан число мужчин в 2,25 раза превышает число женщин, среди сельских жителей - в 2,5 раза [29, с. 24].

Современная таджикская диаспора в Самарской области неоднородна как по социально-экономическим параметрам (от малоквалифицированных рабочих до руководителей бизнес-структур), так и по этнокультурным характеристикам и уровню этнического самосознания. Поэтому результаты опроса, проведенного в Самаре в 2018 г., скорее всего, отражают «в среднем» этнокультурную специфику и опыт социального взаимодействия таджиков с окружением, в то время как на индивидуальном уровне или для представителей разных волн миграции и разных поколений переселенцев они будут значительно отличаться.

Для самарских таджиков, в целом, характерно устойчивое этническое самосознание, основой которого выступает «национальность родителей, предков» $(90,0 \%)$. Вместе с тем на его формирование ожидаемо влияют общность национальных обычаев, культуры, языка и даже «природы» - почти половина указали эти параметры как «сближающие с людьми своей национальности». В то же время для молодого поколения, родившегося и выросшего в Самаре, понятие родины связано не с Таджикистаном, в котором многие ни разу и не были, а с Россией и Самарой [30].

Трансляция этнокультурных традиций происходит, как правило, через семью и родственный круг. При создании семей самарские таджики предпочитали моноэтнические (около 75\%) и моноконфессиональные (92,7\%) браки. Лишь 7,3\% приходится на браки с русскими; среди брачных партнеров представлены также узбеки $(14,6 \%)$ и татары $(2,4 \%)$. Отсюда и преобладающая моноэтничность родственного круга $-80,6 \%$; представители других этнических групп среди родственников немногочисленны - 9,7\% указали узбеков, 6,5\% - русских, 3,2\% - татар. Учитывая тот факт, что четверть браков была заключена уже в Самаре, можно сделать вывод о том, что при выборе брачных партнеров самарские таджики ориентируются на традиционные установки (с таджиками / с мусульманами). В то же время они допускают возможность браков с людьми другой национальности: $40 \%$ информантов заявили, что «национальность при вступлении в брак значения не имеет» и $46 \%$ «точно могут представить брак родственников и друзей с представителями другой национальности». Категоричный отрицательный ответ по этому поводу дали только 6\% опрошенных. Однако в интервью таджикские мужчины чаще высказывались в пользу моноэтничных браков, аргументируя свое мнение тем, что хотели бы иметь в семью привычную модель отношений между ее членами («жена подчиняется мужу», «невестка должна слушаться свекровь») [28].

Примеры немногочисленных межэтнических браков демонстрируют стратегию интеграции в местное сообщество. Например, Д. проживает в Самаре с 1970-х гг., женат на русской, имеет двух сыновей, старший из которых женат на чувашке [30]. С. приехал в Самару в конце 1990-х гг., женился на татарке, с удовольствием рассказывает о сыне, внешне не похожем на таджика («светлые волосы») и успешно изучающем в школе английский язык («лучше русских») [28]. В то же время известны примеры аккультурации иноэтничных членов семей в таджикской среде. Например, Г. - памирец, частный предприниматель, 16 лет живет в Самаре, женат на русской; жена приняла ислам, выучила памирский; дети «памирские таджики» [30]. Данный вариант возможен, вероятно, только при условии существования устойчивой модели трансляции этнокультурного опыта и стабильных внутриэтнических связей в общине, что и будет показано ниже. Этническая самоидентификация детей в браках, включая смешанные семьи, преимущественно «таджикская» $(94,7 \%)$, хотя встречаются и «узбеки», и «метисы», а в русскотаджикских браках - русские [30].

В отличие от брачных контактов круг дружеского общения таджиков в Самаре включает русских (на это указали $86 \%$ опрошенных), татар (42\%) и представителей другой национальности (78\%). Этим данным соответствует и соседское окружение: 96\% проживают по соседству с русскими, 26\% - с татарами, половина - с представителями других национальностей; при этом интенсивность соседского общения достаточно большая - более двух третей $(68 \%)$ имеют «очень частые» и «частые» контакты с соседями. Еще выше $(93,4 \%)$ этот показатель в отношении контактов с коллегами по работе, среди которых также преобладают русские (78\%).

Значительную роль в сохранении этнокультурной идентичности самарских таджиков играют контакты с родственниками на исторической родине. 90,0\% опрошенных поддерживают их регулярно. Общение происходит, как правило, по Интернету $(56,0 \%)$ и телефону (44,0\%); активно используются бесплатные приложения Viber, WhatsApp, Telegram и др. Большинство $(68,0 \%)$ навещают родных раз в году и только 10,0\% - несколько раз в год. Однако пятая часть $(20 \%)$ выезжают редко из-за финансовых проблем $(25,0 \%)$ или занятости на работе $(50,0 \%)$. Примечательно, что $12,5 \%$ из них объясняли свои редкие визиты тем, что «родились в России» и не рассматривают Таджикистан в качестве своей исторической Родины, соответственно, не испытывают желания ездить туда [30]. Еще треть (33,3\%) заявили, что их туда «не тянет». Из интервью: «В 2017 году ездил в 
Таджикистан, не понравилось. Жара. Я уже привык к Самаре. К матери с сыном ездил на машине. Не тянет, не знаю почему. Не хочу там оставаться. Многие говорят, что хотят на Родину, а меня не тянет» [28]. В целом, большинство опрошенных (70\%) продемонстрировало желание чаще бывать на родине предков, что, разумеется, указывает на значимость исторической Родины и родственных связей для самарских таджиков. Вероятно, с привязанностью к родным местам и, одновременно, осознанием временности своего пребывания на самарской земле связан обычай отправлять тела умерших таджиков в Таджикистан [28]. Частые визиты к родственникам в Таджикистан, постоянные контакты по Интернету, по телефону формируют ощущение постоянной включенности в жизнь родственной общины и, в целом, исторической родины. «Я и родину сохранил, и здесь $я$ как на родине», - отметил один из информантов [30].

Таджикский язык - основное средство внутриэтнической коммуникации как в диаспоре, так и с родственниками на исторической родине. Им владеют почти все опрошенные. Этот факт подтверждают и данные переписи: в 2002 г. из 4624 таджиков в Самарской области 4371 чел. или 94,5\% владели родным языком [31]. Однако вторым языком общения в этом же кругу для 80,0\% опрошенных является русский, а еще для $20 \%$ - узбекский; им владеют таджики, переселившиеся из районов смешанного расселения с узбеками. Русский является языком общения на производстве, в быту и в ситуации межэтнических отношений. Высокий уровень функциональности русского языка указывает на ситуацию реального билингвизма, а овладением им - условием успешной интеграции в российское общество. Для повышения уровня владения им некоторые члены общины охотно читают книги на русском языке [28].

Камнем в основании этнокультурной идентичности самарских таджиков являются элементы материального быта, имеющие этническую окраску. Большинство (74\%) имеют их в интерьере своего дома - в основном ковры (в т.ч. сюзане), посуду (в т.ч. деревянные тарелки, пиалы), одежду (в т.ч. тюбетейки, вязаные шерстяные носки джураби), курпачи, картины с видами Таджикистана; в редких случаях можно встретить национальный костюм, музыкальные инструменты, Коран [30]. Большинство предметов несут символическую нагрузку, указывая на причастность к таджикской культуре. Однако в ряде случаев они могут использоваться по прямому назначению: «Когда родственники приезжают, используем. Но я уже сейчас не могу на полу есть, привык за столом. На полу только, когда родственники приезжают... Тюбетейка есть, на праздник надеваю курбан-байрам, ураза-байрам, в гости ходим... Когда праздники с таджиками справляем, сидим на полу, на курпачах» [28].

О блюдах национальной кухни имеют представление почти все опрошенные $(98 \%)$ и $90 \%$ готовят их: преимущественно плов (87,2\%), шорпу (42,6\%), курутоб $(23,4 \%)$, манты $(19,1 \%)$, лагман $(10,6 \%)$, но также шакароб (помидорный салат). Примечательно, что в числе национальных блюд назывались и узбекские (например, суп мастава) и общие для «восточных / азиатских» народов блюда - казан-кебаб, сам$c a$, калла-поча (отварные баранья голова и ноги), $x a$ нум (мучное блюдо, рулет с начинкой из мясного фарша и лука, готовящийся на пару), лаваш, халва и др. В большинстве семей $(70 \%)$ таджикские блюда готовят каждый день, в других - 2-3 раза в месяц. Примечательно, что таджики подчеркивают свои особенности приготовления «общих» для разных этнических групп блюд: например, отличие «таджикского» плова от узбекского или азербайджанского [28]. Блюда национальной кухни сохраняют свою актуальность для выходцев из Таджикистана, ассоциируясь с родиной, в то время как для молодых людей, родившихся и выросших в Самаре, они имеют только утилитарное значение: «Отеи очень мастерски готовит разные пловы с говядиной, бараниной, курицей, какую-то выпечку с мясом. Всё очень вкусно, но относятся ли эти блюда к таджикской наџиональной кухне - не знаю. Таким вопросом не задавался» [30].

В целом, формирование и существование таджикской общины как этнической целостности связано с декларированием и воспроизводством традиционных ценностей, которые они противопоставляют культуре принимающего большинства. «Хоть в России живем, но у нас другие законыл», - отмечают информанты, подразумевая различия в менталитете, обычаях. В числе последних - уважение к старшим, почитание родителей, следование традициям, сдержанность при публичном выражении чувств и другие [28].

Самарские таджики интегрированы в многонациональную мусульманскую общину города, практически все считают себя верующими мусульманами. Вместе с тем религиозность выражается на индивидуальном уровне по-разному: регулярно посещают мечеть, читают Коран и соблюдают все религиозные обряды только треть (34\%), 36,2\% иногда посещают мечеть и соблюдают некоторые религиозные обряды, а $29,8 \%$ ограничиваются признанием веры в Бога. Ежедневно посещают храм менее четверти - 22,9\%, столько же бывают в нем по праздникам, несколько больше приходящих в мечеть еженедельно (33,3\%). На этом фоне $20,8 \%$ тех, кто совсем не ходит в мечеть, выглядит внушительно. Религиозность самарских таджиков в условиях полиэтничной городской среды проявляется, скорее, не в посещении культовых мест, а через проведение религиозных (мусульманских) праздников - Курбан-байрам, Ураза байрам / Ураза айт (их празднуют от половины до 62\% опрошенных), соблюдение поста (12,2\%).

В числе «таджикских» праздников наиболее популярен Новруз - его отмечают 77,1\% опрошенных, для трети из них он является любимым праздником. Если в семейно-родственном кругу и при праздновании с друзьями-таджиками он действительно становится одной из площадок этнической консолидации, то в формате межэтнического праздника «Навруз» с участием других национально-культурных центров народов Средней Азии, Казахстана, Кавказа является средством межэтнической интеграции.

В праздничный календарь самарских таджиков вплетены светские и государственные праздники (Новый год, 8 Марта, 9 Мая и другие), объединяющие их с другими этническими группами.

Определенную роль в адаптации мигрантов к полиэтнической среде региона играют общественные организации. В 2001 г. была создана Самарская областная общественная организация «Содействие развитию таджикской культуры «Сомоньен» («Единство»), целью которой является сохранение и развитие таджикского языка и культуры, национальных традиций и обычаев. В 2010 г. она была преобразована в Самарскую областную общественную органи- 
зацию таджикистанцев «Пайванд-Единство». Организация участвует в межнациональных мероприятиях, проводит литературные вечера, посвященные известным таджикским поэтам и писателям, День Республики Таджикистан (9 сентября), устраивает гастроли артистов из Таджикистана. При обществе создан ансамбль «Садо» (Голос), действует воскресная школа. Председателем правления многие годы является Юсуфов Даврон Юсуфбекович. В Тольятти интересы таджиков представляет Автономная некоммерческая организация «Поддержка культуры таджиков», члены которой, в частности студенты вузов, проводят культурно-просветительские мероприятия, знакомящие другие народы с обычаями таджиков [8].

Несмотря на то, что в многонациональном окружении самарские таджики позиционируют себя как единая этническая общность, внутриэтническое разделение (равнинные / горные, выходцы из разных историко-культурных областей) сказывается на особенностях коммуникации членов общины. Различия в диалектах и культурная специфика способствуют предпочтительному общению земляков, в первую очередь, консолидации памирцев - выходцев из Горно-Бадахшанской автономной области Республики Таджикистан. В составе «Местной таджикской национально-культурной автономии г.о. Самара» выделяется памирская община. Ее активисты провели 26 мая 2018 г. праздник «Рузи Нур»- «День Света», приуроченный к дате первого исторического визита в Таджикистан духовного лидера исмаилитов всего мира Имама Карима-ал-Хусайни - Ага Хана IV [32].

Другая не менее значимая сеть социального взаимодействия - родственные связи, через которые в основном осуществляется приток и адаптация мигрантов в регионе. Помощь при переезде, получении регистрации, трудоустройстве - важнейший фактор трудовой миграции таджиков.

Третий уровень внутриэтнических контактов обусловлен формирующимися на месте знакомствами: «При общении выясняем - ты брат этого, племянник того, помогаем... деньгами, если очень хорошо знаком с человеком» [28]. Плотная сеть внутриэтнических связей позволяет оперативно оказывать финансовую помощь нуждающимся, особенно в случае смерти родственников: «Помогают друг другу. Собирают деньги. Отправляют на родину. Сборщики приходят, говорят: «Ты такого-то знаешь? Умер». Я отдаю. Без вопросов. Иногда сам собираю. Сейчас это можно и по Интернету» [28]. В земляческой среде распространена взаимопомощь [30].

Приоритет внутриэтнических контактов проявляется и в идеальных моделях интеграции в местную среду, в которые, наряду с обретением материального благополучия, а для молодых - также с получением образования и приобретением профессии, вписана картина комфортной семейно-родственной обстановки - этнического микросоциума: «Хочу культурно ходить, красиво одеваться... Сельский дом - дачу в пределах 70 километров от Самары. Хочу привезти семью, родителей; чтобы они без дела не сидели, корову заведу, чтобы было молоко. Буду ездить на машине. Неделю буду работать, а на выходные в деревню...» [28]. (Этот сюжет соответствует распространенной среди значительной части горожан в России модели социального поведения (работать в городе, жить и отдыхать на даче), поэтому может быть интерпретировано как стремление приблизить- ся к стандартам жизни местного населения). В целом, устойчивые внутриэтнические контакты выступают одним из основных факторов консолидации общины, сохранения и воспроизводства этнической идентичности, но в то же время - фактором интеграции таджикской диаспоры в Самаре в социокультурное пространство региона.

\section{Заключение}

Основными факторами этнокультурной идентификации самарских таджиков выступают язык, общность происхождения и элементы этнической культуры, представленные в семейно-родственном общении, а также в публичном пространстве региона. Этнические (таджикские) приоритеты в конструировании социокультурного пространства обеспечивают функциональность и воспроизводство культурноязыковых характеристик членов общины и определяют тенденцию к внутриэтнической замкнутости. Вместе с тем контакты с окружающим полиэтническим населением и установка на интеграцию в местную среду (получить образование, гражданство, работу, устроить быт) разрушают моноэтничность социальных связей самарских таджиков, в первую очередь молодого поколения, родившегося в России. Таким образом, стратегия социокультурной интеграции самарских таджиков основана на сохранении этнокультурной идентичности, с одной стороны, и восприятии социальных характеристик принимающего сообщества, с другой стороны.

\section{Список литературы:}

1. Всероссийская перепись населения 2010 года. Национальный состав населения Российской Федерации [Электронный ресурс] // Демоскоп Weekly. http://demoscope.ru/weekly/ssp/rus_nac_10.php.

2. Амелин В.В. Таджики в Оренбуржье (Очерки современных этносоциальных процессов). Оренбург: ООО ИПК «Университет», 2013. 104 с.

3. Всесоюзная перепись населения 1989 года. Национальный состав населения по регионам России [Электронный ресурс] // Демоскоп Weekly. http://demoscope.ru/weekly/ssp/rus_nac_89.php?reg=37.

4. Всероссийская перепись населения 2002 года. Национальный состав населения по регионам России [Электронный pecypc] // Демоскоп Weekly. http://demoscope.ru/weekly/ssp/rus_nac_02.php?reg=55.

5. Всесоюзная перепись населения 1939 года. Национальный состав населения по регионам России [Электронный pecypc] // Демоскоп Weekly. http://demoscope.ru/weekly/ssp/rus_nac_39.php?reg=33.

6. Всесоюзная перепись населения 1970 года. Национальный состав населения по регионам России [Электронный pecypc] // Демоскоп Weekly. http://demoscope.ru/weekly/ssp/rus_nac_70.php?reg=37.

7. Всесоюзная перепись населения 1979 года. Национальный состав населения по регионам России [Электронный pecypc] // Демоскоп Weekly. http://demoscope.ru/weekly/ssp/rus_nac_79.php?reg=37.

8. Таджикские общественные организации в Самарской области [Электронный ресурс] // Бюро переводов «Слово». - http://perevod63.ru/articles/tadzhikskie obschestvennye_organizacii_v_samarskoy_oblasti.html.

9. Ашкинази Л., Гейнер М. Численная мультистатусная модель диаспоры // Диаспоры. 1999.№ 2. C. $34-39$.

10. Коэн Д. От Маккавеев до Мишны / пер. с анг. М. Вогмана и А. Крупновой. М.: Книжники, 2014. 288 с. 
11. Сафран У. Сравнительный анализ диаспор. Размышления о книге Робина Коэна «Мировые диаспоры» // Диаспоры. 2004. № 4. С. 140-164.

12. Шеффер Г. Диаспоры в мировой политике // Диаспоры. 2003. № 1. С. 162-184.

13. Арутюнов С.А. Диаспора - это процесс // Этнографическое обозрение. 2000. № 2. С. 74-79.

14. Дятлов В.А. Диаспора: попытка определиться в понятиях // Диаспоры. 1999. № 1. С. 8-23.

15. Тишков В.А. Исторический феномен диаспоры // Этнографическое обозрение. 2002. № 2. С. 43-63.

16. Дятлов В. Что такое диаспора? // Дятлов В. Мелконян Э. Армянская диаспора: очерки социокультурной типологии. Ереван: Ин-т Кавказа, 2009. C. 7-35.

17. Иванова Т.Д. Таджики в московском социуме // Иммигранты в Москве / под ред. Ж.А. Зайончковской. М.: Три квадрата, 2009. С. 176-208.

18. Флоринская Ю. Памирские трудовые мигранты в России (по результатам исследования в московском регионе) [Электронный ресурс] // Демоскоп Weekly. № 415-416. 22 марта - 4 апреля 2010 г. http://demoscope.ru/weekly/2010/0415/analit01.php.

19. Олимова С., Боск И. Трудовая миграция из Таджикистана. Душанбе: Предст-во Межд. орг. по миграции, 2003. 145 с.

20. Каландаров Т.С. Памирские мигранты-исмаилиты в России // Исследования по прикладной и неотложной этнологии. № 178 / отв. ред. В.А. Тишков. М.: ИЭА РАН, 2005. 29 c.

21. Зотова Н.А. Трудовая миграция из Таджикистана. По материалам полевого исследования в Москве и Самаре [Электронный ресурс] // Фергана. Информационное агентство. - https://fergananews.com/articles/4424.

22. Черных А.В. Таджики в Перми. Очерки этнокультурного развития. Пермь: Изд-во Пермского образоват. науч.-иссл. Центра авитальной активности, 2004. $28 \mathrm{c}$.

23. Черных А.В. Этносоциальные процессы в таджикской диаспоре Пермского края на современном этапе (по материалам этносоциологического исследования). Пермь: Изд-во ПОНИЦАА. 2006. 148 с.

24. Габдрахманова Г.Ф., Сагдиева Э.А. Таджики и узбеки в Республике Татарстан: биографии диаспоры и повседневные практики. монография. Казань: Ин-т истории им. Ш. Марджани АН РТ, 2016. 100 с.

25. Мухаметшина Н.С. Проблемы интеграции мигрантов в региональный социум // Известия Самарского научного центра Российской академии наук. 2013. T. 15, № 1. С. 138-142.

26. Мухаметшина Н.С. Мигранты из государств Центральной Азии в Самарской области // Известия Самарского научного центра Российской академии наук. 2018. Т. 20, № 3 (2). С. 557-561.

27. Эркаев С.А., Эркаев А.С. Таджикские мигранты в этнокультурном пространстве Башкортостана // Проблемы востоковедения. 2015. № 2 (68). С. 20-25.

28. Полевые материалы автора, 2018. г. Самара.

29. Национальный состав Самарской области (по данным Всероссийской переписи населения 2010 года). Статистический сборник. Самара: Самарастат, 2013. $327 \mathrm{c}$.

30. Материалы полевого исследования по проекту 18-411-630002, Самара, 2018.

31. Национальный состав и владение языками, гражданство. Население по национальности и владению русским языком по субъектам Российской Федерации [Электронный ресурс] // Всероссийская перепись населения 2002 года. - http://perepis2002.ru/?id=17.

32. «Нур» - праздник света и веры в будущее [Электронный ресурс] // Портал о дружбе народов «Bсе мы - Россия!». - https://samddn.ru/novosti/novosti/ nur-prazdnik-sveta-i-very-v-budushchee/.

Исследование выполнено при финансовой поддержке РФФИ и Самарской области в рамках научного проекта 18-411-630002 «Изучение феномена социокультурной интеграции мигрантов из государств Центральной Азии в Самарской облаcmu».

\section{«I HAVE PRESERVED MY HOMELAND, AND HERE I AM, LIKE IN MY HOMELAND»: FEATURES OF ETHNOCULTURAL IDENTIFICATION AND SOCIOCULTURAL INTEGRATION OF SAMARA TAJIKS}

(C) 2019

Iagafova Ekaterina Andreevna, doctor of historical sciences, professor, head of Philosophy, History and Theory of World Culture Department Samara State University of Social Sciences and Education (Samara, Russian Federation)

Abstract. The paper presents the study results of the Tajik diaspora in Samara Region. The features of ethnic identification and socio-cultural adaptation of the community members were identified. The study is based on the materials from a field survey conducted in the region in 2018-2019, using qualitative (in-depth interviews) and quantitative methods (questionnaires). The methodology of the paper is based on theoretical and methodological developments in the field of diasporal research. The main factors of ethnocultural identification of Samara Tajiks are the language, community of origin and elements of ethnic culture represented in family-kinship communication, as well as in the public space of the region. Ethnic (Tajik) priorities in the construction of sociocultural space provide the functionality and reproduction of the cultural and linguistic characteristics of community members and determine the tendency to interethnic isolation. At the same time, contacts with the surrounding multiethnic population and the orientation towards integration into the local environment (to get education, citizenship, work, arrange living) destroy mono-ethnicity of Samara Tajiks social ties, primarily those of the young generation born in Russia. The study showed that the strategy of socio-cultural integration of Samara Tajiks is based on the preservation of ethnocultural identity, on the one hand, and the perception of the social characteristics of the host community, on the other.

Keywords: Samara Tajiks; diaspora group; community; migration; ethnic culture; ethnocultural identity; sociocultural integration; adaptation; interethnic contacts; interethnic marriages; national cuisine; holidays; religion; multiethnic environment. 